\title{
STERILITY TESTING OF PLATELETS CONCENTRATE WITHIN QUALITY CONTROL: EXPERIENCES AND OPPORTUNITIES TO EXTEND THE APPLICATION
}

\author{
Dragana Gojkov ${ }^{1}$, Nemanja Borovcanin ${ }^{1}$ and Dusan Vucetic ${ }^{1,2}$ \\ ${ }^{1}$ Institute for Transfusiology and Hemobiology, Military Medical Academy, Belgrade, Serbia \\ ${ }^{2}$ Faculty of Medicine, Military Medical Academy, University of Defence, Belgrade, Serbia
}

Received: 10.02.2020.

Accepted: 22.02.2020.

\section{Corresponding author: \\ Dragana Gojkov, MD}

Institute for transfusiology and hemobiology Military Medical Academy, Crnotravska 17, Belgrade, Serbia

Phone: +381113609177

E-mail: jovidrag@gmail.com

\section{sciendo}

UDK: 616.94-074

Eabr 2023; 24(1):27-32

DOI: $10.2478 /$ sjecr-2020-0014

\begin{abstract}
Despite numerous measures, bacterial sepsis associated with the transfusion remains a major threat. The incidence of septic events induced by platelets transfusion is approximately 10 times higher than with transfused red blood cells due to their storage temperature. This caused new Standard that implements the methods for the detection and reduction of bacteria in the platelet concentrates $(P C)$. The aim is to consider the possibility of wider application of this tests in order to extend the shelf-life of PC. Sterility testing of $P C$ is done once or twice per month using BacT/Alert BPA and BacT/Alert BPN bottles. If positive, all products from the initial unit were tested to confirm or deny the status. During six years period, 67236 PC units were made and 872 of them were tested. Only two were found initially positive. After testing the other products from the same initial unit, results were negative so, final results proclaimed false positive. Pretransfusion bacterial detection is an important potential method for reducing the risk of bacteriemia and transfusion-associated septic reactions. In addition to routine measures, Mirasol PRT pathogen inactivation system, could be included. This allows certain amount of PC to be inactivated during the first 32 hours. Untreated PC units would be stored in standard conditions and for given time (three days) potentially present bacteria would reach a detectable level. This way the quantity of samples for sterility testing could be reduced, taking only $2 \mathrm{ml}$ of each of four units of PC. Samples would be planted at the same vial-aerobic bottle, which would also, double the capacity in BacT/Alert $3 D$ automated system.
\end{abstract}

Keywords: Platelets, bacterial sepsis, sterility control, shelf life. 


\section{INTRODUCTION}

Introduction of the routine use of a closed system of plastic bags for blood collection, processing under sterile conditions that such system allows and adequate storage, enables significantly enhanced sterility of blood components. Despite these measures, bacterial sepsis associated with the transfusion remains a major threat and is a topic constantly repeated in the literature over the past 40 years. The incidence of septic events induced by platelets transfusion is approximately 10 times higher than with transfused red blood cells (1). Platelet concentrates (PC) are the most common cause of bacterial infections. A retrospective study conducted at the National Blood Service, North London Centre, found that the rate of bacterial contamination is $0.7 \%$ and $0.4 \%$ in pooled and apheresis platelets respectively (2).

Possible strategies in order to reduce bacterial contamination and transmission include detailed screening of donors, improvement of disinfection of the venipuncture site, removing the initial blood into sampling pouch (the first $10-20 \mathrm{ml}$ of blood) and sterility controlling in automated systems (1, 2).

Given the frequency of bacterial contamination, on March 2004 the American Association of Blood Banking (AABB) announces a new Standard that implements the methods for the detection and reduction of bacteria in the PC $(3,4)$. At the Institute for Transfusiology and Hemobiology of Military Medical Academy (MMA) sterility control of PC was first performed in 1997. Routine sterility testing as the part of the quality control of PC started in 2008. Implementation of screening of PC on bacterial contamination, according to the global data (5-9), successfully identified the contaminated products and reduced transfusion of such products to the patients.

The aim of this study was to evaluate the results of routine PC sterility testing as part of the quality control. Also, according to these results and data from the literature, regarding the frequency of bacterial transmission by PC transfusion, consider the possibility of wider application of this test in order to extend the shelf-life of PC from five to seven days.

\section{MATERIALS AND METHODS}

Whole blood $(450 \pm 45 \mathrm{ml})$ was collected from random healthy donors, age 18-65 years, after adequate disinfection of venipuncture site and removing the initial blood into sampling pouch (the first 10-20 $\mathrm{ml}$ of blood). We used quadruple bags Macopharma (Macopharma, France) and Terumo (Terumo, Japan) with citrate-phosphate-dextrose (CPD) as anticoagulant-conserving solution and SAGM (sodium chloride-adenine-glucose-mannitol) as additive solution for red blood cells (RBC). Primary separation (separation of RBC, fresh frozen plasma - FFP and buffy coat - BC) of whole blood units was performed after 2-8 hours of collection by centrifugation in a centrifuge JOUAN (Jouan, France).
Parameter settings were: speed $3603 \mathrm{rpm}$ (3890 g) for 10 minutes at $22 \pm 2{ }^{\circ} \mathrm{C}$ (the radius $-\mathrm{R}=268 \mathrm{~mm}$, acceleration - $\mathrm{A}=6$, brake - $\mathrm{B}=4$ ). Separation was performed on the automatic separator T-ACE II (Terumo, Japan). Secondary separation was performed after BC resting overnight at ambient temperature. Parameter settings: speed $1170 \mathrm{rpm}$ (377 g) at $22 \pm 2{ }^{\circ} \mathrm{C}$ for 5 minutes $(\mathrm{R}=245 \mathrm{~mm}, \mathrm{~A}=2, \mathrm{~B}=0)$. The resulting platelet concentrate from the buffy coat (PC$\mathrm{BC}$ ) were kept in a shaker for platelets at a temperature of 22 $\pm 2^{\circ} \mathrm{C}$. Donors were non-reactive for hepatitis $\mathrm{B}$ and $\mathrm{C}$ virus (HBV and HCV), human immunodeficiency virus (HIV) and lues markers - investigated by chemiluminescent immunoassay (Architect, Abbott, USA), as well as by NAT testing (Cobas AmpliPrep and Amplicor Analyzer, Roche, Germany)

Sterility testing of PC-BC was done once or twice per month to ten samples minimum. Samples were collected in BacT/Alert BPA and BacT/Alert BPN bottles for liquid culture of aerobic and anaerobic bacteria (BioMerieux, Durham, NC, USA). After proper marking, plastic caps were removed from bottles and rubber top disinfected with $70 \%$ ethyl alcohol and left to dry for 30 seconds. Hose of PC-BC bag whose sterility is examined, is cleaned with $70 \%$ ethyl alcohol and allowed to dry. On the clip corresponding to the diameter of the bottle is placed a sterile disposable needle and when the hose is dry, needle entered disinfected part. In the clip is placed BacT/Alert bottle in which is withdrawn (due to negative pressure) $4-8 \mathrm{ml}$ of the bag contents. After that, the bottle is removed from the clip. In the same way is taken the content into the other bottle and before the needle is pulled out, the hose is sealed between the needle and the bag. The bottles were placed in the BacT/Alert 3D automated system for liquid cultures for the incubation period of five days. Capacity of device is 60 bottles at the time. Samples were taken from the PC-BC unit fifth or sixth day of their storage, provided that the blood collecting day counts as day zero.

Really positive PC-BC unit is considered if the same microorganism, detected in the $\mathrm{PC}-\mathrm{BC}$ sample, is isolated from all available products derived from the same whole blood. A false positive PC-BC unit is in the case other products obtained from the initial whole blood unit remain sterile, ie. microorganism was not isolated. In this case probable reason for sample PC-BC positivity is inadequate disinfection and manipulation during sampling.

\section{RESULTS}

Routine sterility testing of PC in our Institute began in 2008 year. Until July 2010, except for sampling, the whole process took place at the Institute of Microbiology, and after that, when the Institute for Transfusion and Hemobiology got its own BacT/Alert 3D automated system for liquid bacterial culture, the process is handled entirely by the Department of blood products with quality control. 
During the 2008109 samples were tested on sterility, 2009 only 35 (due to the small capacity of the incubator and major requirements for blood culture testing from other clinics), 2010172 sample, 2011209 samples, 2012159 samples and 2013188 (Table 1). Among these 872 samples, positivity was detected only twice in aerobic microflora detection bottles (ones 2008 and 2011 second time). In both cases,
Coagulasa positive Staphylococcus was isolated, but positivity was false, as other products from the same initial blood unit remained sterile after five days of incubation.

In the same period (since 2008 till 2013) 67236 units of PC-BC were made. Not one really positive sample was detected. The percentage of false positives was $0.2 \%$.

Table 1. Number of PC-BC tested during five years

\begin{tabular}{|l|c|c|c|c|c|c|}
\hline $\begin{array}{c}\text { YEAR } \\
\text { PC-BC }\end{array}$ & 2008. & 2009. & 2010. & 2011. & 2012. & 2013. \\
\hline Total PC-BC number & 10015 & 10324 & 10767 & 10816 & 12264 & 13050 \\
\hline $\mathrm{N}^{\circ}$ PC-BC tested & 109 & 35 & 172 & 209 & 159 & 188 \\
\hline $\mathrm{N}^{0}$ PC-BC tested pos. & 0 & 0 & 0 & 0 & 0 & 0 \\
\hline $\mathrm{N}^{0}$ falsely positive (\%) & $1(0.92)$ & 0 & 0 & $1(0.48)$ & 0 & 0 \\
\hline
\end{tabular}

\section{DISCUSSION}

In the United States during the period from 1986 to 1991 years, bacterial contamination was the cause of $15.9 \%$ of all fatalities regarding transfusion. In France, between 1994 and 1998 there were 18 deaths as a result of bacterial contamination of blood components. In the UK, from 1995 to 2000, there were 26 transfusion transmitted infections, in 15 cases the cause was bacterial infection (2). In the most of these cases, bacterias are detected in units of PC (1 in 2,000 to 1 in $1,000)(10,11)$. From the data on the incidence of bacterial contamination of blood products, the governments of many countries, have given the recommendation to test for bacterial contamination within the "Quality Control". This is a good step to improve the safety of blood products, but the clinical significance (benefit for a medical institution) is still limited. If we assume that the degree of platelet contamination is $0.2 \%$ (3), then in our case, when tested $1.3 \%$ of all PC units (872 out of 67236), the chance to detect a contaminated product is $1.3 \% \times 0.2 \%=0.0026 \%$. This means that the possibility of contaminated product to be given to the patient is still very high, although the role of quality control of the process is undeniable, since, in the case of continued failure in the production process as a possible source of contamination, the center would be alerted that something was wrong with the process.

However, the real answer to potential bacterial contamination of PC and transfusion of such products to patient is screening. Screening means testing $100 \%$ of the PC units on bacterial contamination (12). Four elements are necessary for transmission of infectious agents by blood transfusion:

1. Asymptomatic phase while the microorganism (MO) is present in the blood,

2. MO viability must be preserved during storage,

3. There must be a population of seronegative recipients,

4. MO must be able to cause disease.
A unique aspect of most bacterial species compared with viruses is their ability to easily proliferate in, for them, very nourishing blood products during storage. This is especially true for PC units that are stored at ambient temperature. It has been calculated that the level of contamination at the time of collection is generally low, probably only 1-10 colony forming units $(\mathrm{CFU}) / \mathrm{ml}$ or less. However, when the product is contaminated, the bacteria can multiply so quickly that in a few hours reaches the level of $10^{6} / \mathrm{ml}$ or more. If product with such amount of bacteria was transfused, in a short time could cause bacteremia, which can progress to sepsis and death. The outcome of the contaminated blood transfusion depends of the amount of bacteria, types of bacteria and its pathogenicity for man, transfusion rate and clinical status of the patient. Immunosuppressed patients and elderly people with poor nutritional status are the most vulnerable populations, although fatal deaths in healthy people are not rare, especially in case of transfusion of large amount of Gram-negative bacteria that produce endotoxin.

Possible sources of bacteria in blood components may be: donor's bacteremia, contamination during collection and processing of blood, as well as the contamination of blood collection sets.

Blood donors with asymptomatic bacteremia or in recovery from a bacterial infection, can regardless of transient bacterial episode be eligible for donation, of which there are numerous data in the literature (sepsis caused by Yersinia enterocolitica) $(13,14)$. Short-term bacteremia may occur after certain dental manipulations, especially the extraction of teeth, and there were cases of contamination of PC with Staphylococcus aureus as a result of this situation (12).

However, the greatest risk of bacterial contamination is during blood collection, so, the most of the microorganisms isolated from contaminated PC is actually normal microflora of the skin, as it is virtually impossible to completely 
decontaminate the venipuncture site. It is also thought that a small amount of skin can enter the needle during venipuncture and allow the entry of viable bacteria from the deeper layers of the skin despite adequate disinfection of surfaces (15).

Improperly sealed or damaged hoses, micro damages of collection bags, were associated with episodes of bacterial sepsis as well (16).

Therefore, measures for the prevention of bacterial contamination of blood products would be:

A. Reducing the risk of contamination during blood collection: an improved screening of blood donors; enhanced disinfection of venipuncture site; removing the initial blood into sampling pouch,

B. Optimization of processing and storage of blood components: optimization of storage temperature; limited storage time; universal leukoreduction,

C. Reducing the exposure of the patient to blood donors,

D. Pretransfusion bacterial detection: visual inspection of components prior to issuance; direct staining of bacteria; bacterial ribosomal essay; assay for bacterial endotoxin; nucleic acid testing (NAT) for bacterial DNA; measurement of $\mathrm{CO}_{2}$ production or $\mathrm{O}_{2}$ consumption by bacteria; direct bacterial cultures,

E. Introduction of pathogen reduction / inactivation.

Pretransfusion bacterial detection is an important potential method for reducing the risk of bacteremia and transfusion-associated septic reactions, but none of currently available laboratory techniques is ideal. Automatic systems for liquid cultures are the most sensitive method used in transfusion centers and are currently widely used (17). Two of these systems are granted in the United States:

1. BacT/Alert (BacT/Alert; BioMerieux, Durham, NC) uses the bottles with the substrate and colorimetric sensor that changes color as a result of increased production of $\mathrm{CO}_{2}$ generated during cell growth. Two bottles (aerobic and anaerobic) are used; in each is inoculated 4-8 ml of PC. Since the needle is used for inoculation, the system is not completely closed. The system is extensively validated with a wide range of potentially contaminating MO. The method reliably detects PC contamination when $10 \mathrm{CFU} / \mathrm{ml}$, in many cases, even $5 \mathrm{CFU} / \mathrm{ml}$ of bacteria is inoculated (eg, B.cereus, S.marcescens, C. perfringens, S.epidermidis, S.pyogenes, E.coli, K.pneumoniae, S.aureus and S.viridans) for 12 to 26 hours, while for the detection of Propionibacterium acnes (whose clinical significance is debatable), require longer incubation time $(1,2,10,18-21)$. In most works this system is used as a reference (22).

2. Another system for bacterial culture is Pall Bacterial Detection System (BDS). Sampling is done so that the system remains effectively closed: about 5-6 ml of leukoreduced platelet rich plasma is taken from the bag and passed through a filter (to remove residual leukocytes, platelets, and about $50 \%$ of bacteria) in the incubation bag. Incubation bags containing sodium polianetol sulfonate that enhances the growth of gram-negative organisms. Incubation at $35^{\circ} \mathrm{C}$ is for at least 24 hours before the measurement of oxygen concentration in the upper part of the bag, which decrease to $19.5 \%$ or lower indicates bacterial growth. This means that the system does not detect the obligatory anaerobes. In trials with 10 well-known platelet contaminants at a dose of 100 to 500 $\mathrm{CFU} / \mathrm{ml}, 96.5 \%$ were detected in the first 24 hours, and $100 \%$ for $30 \mathrm{~h}$. However, some external validation study showed a lower than expected sensitivity of S.epidermidis and S.agalactiae (3).

3. BACTEC FX System is a recently introduced automated system for haemoculture, used in Korea; detects growth of $\mathrm{MO}$ with fluorescent sensors for $\mathrm{CO}_{2}$.

In clinical microbiology laboratories a five-day incubation protocol is generally used (17). As the level of bacteria that is present at the time of blood or PC donation is low, detection is limited by several factors, including the initial bacterial titer, size and time of sample collection for testing and the kinetics of growth of some bacteria. Low levels of bacteria at the time of donation, especially those slow growing, is a challenge for most methods of cultivation and requires preincubational period of at least 24 hours before sampling and subsequent 24 hours for incubation. However, several studies have shown that the percentage of undetected bacterial contamination, when the initially negative units sowed the fifth or seventh day of storage, range from $13 \%$ to $43 \%$. As of slow growing bacteria in question was mainly Propionibacterium acnes who is considered to be clinically insignificant, the rate is reduced to $6 \%(2,18,23-25)$.

Another important factor of sampling is the sample size. Unlike apheresis units that contain $200-250 \mathrm{ml}$ of products, PC units extracted from random donors' blood units, have volume of 45-65 ml. Therefore, the amount of sample needed to inoculate the aerobic and anaerobic bottle (total of 8-16 $\mathrm{ml}$ ), would significantly reduce the amount of products for transfusion $(2,18,24)$. On the other hand, McDonald and colleagues showed in their study that the inoculation of $2 \mathrm{ml}$ of PC-BC in Pedi-BacT (pediatric, aerobic) Bact/Alert bottle, was sufficient to detect any bacteria in the reporting period (other than P. Acnes), present in quantity of 10-100 CFU $/ \mathrm{ml}$ (18). Also, of the most commonly isolated bacterial pathogens that are related with transfusion induced bacteremia and sepsis: Gram-positive Staphylococcus epidermidis, S. Aureus, Streptococcus agalactiae, B. Cereus, E. faecalis, S. Pneumoniae, and Gram-negative E. coli, Enterobacter aerogenes, E. cloacae, P. rettgeri and Y. enterocolitice, only Cl.perfrigens is anaerobic MO. Fortunately, these bacteria grow in aerobic and anaerobic bottles $(2,11,18,23,24,26)$ and Mastronardis study (20) showed a lower sensitivity of the anaerobic bottle.

The frequency of clinically diagnosed septic episodes as a result of transfusion of contaminated products is significantly reduced with respect to the existing data on bacterial 
contamination of blood products, particularly platelets (3). The probable reason is that serious, even fatal sepsis cases go unrecognized as a result of transfusion, which means that the actual prevalence of septic transfusion reactions is significantly higher than reported. An aggravating circumstance is that the septic reactions due to transfusion of contaminated products can easily be unrecognized as such because of the high incidence of febrile nonhaemolytic transfusion reactions (FNHTR), especially after platelet transfusion. Incidence rate of FNHTR after platelet transfusion may be up to $15 \%$. Since the symptoms of septic transfusion reactions are similar to those of FNHTR, many mild septic reactions may remain unrecognized as such. In addition, most MO isolated from contaminated unit PC are normal skin flora (eg, Gram-positive cocci) and is often considered a consequence of contamination during the sampling process, ie. false positive $(3,14,23)$.

\section{CONCLUSION}

Since there is a great need for platelets in our hospital, we think that common practice of PC sterility control could be used to extend the shelf-life of platelets. Specifically, in addition to routine measures, such as detailed donors' screening, good disinfection of venipuncture site and removing the initial blood into sampling pouch, Mirasol PRT pathogen inactivation system, used in our facility, could be introduced. Certain amount of PC, could be inactivated during first 32 hours after separation, as recommended by the manufacturer, and be ready for clinical use. Unused PC units would be stored in standard conditions and for given time (three days) potentially present bacteria have time to reach a detectable level. In this way we could reduce the quantity of samples for sterility testing (and thus provide an adequate amount of product for transfusion), taking only $2 \mathrm{ml}$ of each of four units of PC, which would be inoculated at the same vial. Based on data from previous studies, only one, aerobic bottle, would be sufficient, which would also, double the capacity in BacT/Alert 3D automated system. Since all PC units are treated/tested, shelf-life could be extended from five to seven days.

\section{ACKNOWLEDGMENT}

This work was supported by the Faculty of Medicine, Military Medical Academy, University of Defence, Belgrade (Project MFMMA9/17-9).

\section{ETHICS APPROVAL}

The study was conducted in accordance with the ethical standards of the committee responsible for human experimentation (institutional and national) and the Helsinki Declaration of 1975, as revised in 2013.

\section{CONFLICT OF INTERESTS}

The authors declare no conflicts of interest.

\section{FUNDING}

None.

\section{REFERENCES}

1. Wagner SJ, Robinette D. Evaluation of an automated microbiologic blood culture device for detection of bacteria in platet components. Transfusion. 1998;38:674-9.

2. McDonalds CP, Roy A, Lowe P, Robbins S, Hartley S, Barbara JAJ. Evaluation of the BacT/Alert automated blood culture system for detecting bacteria and measuring their growth kinetics in leucodepleted and non-leucodepleted platelet concentrates. Vox Sang. 2001;81: 154-160.

3. Hillyer CD, Josephson CD, Blajchman MA, Vostal JG, Epstein JS, Goodman JL. Bacterial Contamination of Blood Components: Risks, Strategies, and Regulation. Hematology Am Soc Hematol Educ Program. 2003:57589.

4. Goodrich RP, Gilmour D, Hovenga N, Keil SD. A laboratory comparison of pathogen reduction technology treatment and culture of platelet products for addressing bacterial contamination concerns. Transfusion. 2009; 49:1205-16.

5. Fang CT, Chambers LA, Kennedy J, Strupp A, Fucci MC, Janas JA, et al. American Red Cross Regional Blood Centers. Detection of bacterial contamination in apheresis platelet products: American Red Cross experience, 2004. Transfusion. 2005;45:1845-52.

6. Ramírez-Arcos S, Jenkins C, Dion J, Bernier F, Delage G, Goldman M. Canadian experience with detection of bacterial contamination in apheresis platelets. Transfusion. 2007; 47:421-9.

7. Janssen MP, van der Poel CL, Buskens E, Bonneux L, Bonsel GJ, van Hout BA. Costs and benefits of bacterial culturing and pathogen reduction in the Netherlands. Transfusion. 2006;46:956-65.

8. Kleinman SH, Kamel HT, Harpool DR, Vanderpool SK, Custer B, Wiltbank TB, et al. Two-year experience with aerobic culturing of apheresis and whole blood-derived platelets. Transfusion. 2006;46:1787-94.

9. De Korte D. 10 Years Experience with Bacterial Screening of Platelet Concentrates in the Netherlands. Transfus Med Hemother. 2011;38:251-4.

10. Brecher ME, Heath DG, Hay SN, Rothenberg SJ, Stutzman LC. Evaluation of a new generation of culture bottle using an automated bacterial culture system for detecting nine common contaminating organisms found in platelet components. Transfusion. 2002;42:774-9.

11. Brecher ME, Hay SN, Rothenberg SJ. Monitoring of apheresis platelet bacterial contamination with an automated liquid culture system: a university experience. Transfusion. 2003;43:974-8.

12. Lockhart P, Brennan M, Sasser H, Fox P, Paster B, Bahrani-Mougeot F. Bacteremia associated with tooth brushing and dental extraction. Circulation. 2008; 117(24):3118-3125. 
13. Grossman BJ. Kollins P, Lau PM, Perreten JL, Bowman RJ, Malcolm S et al. Screening blood donors for gastrointestinal illness: a strategy to eliminate carriers of Yersinia enterocolitica. Transfusion 1991; 31: 500-1.

14. Brecher ME, Hay SN. Bacterial Contamination of Blood Components. Clinical Microbiology Reviews 2005; $195-$ 204.

15. Goldman M, Blajchman MA. Blood product-associated bacterial sepsis. Transfus Med Rev. 1991;5:73-83.

16. Hogman CF, Engstrand L. Serious bacterial complications from blood components-how do they occur? Trans Med. 1998;8:1-3.

17. Roh KH, Kim JY, Kim HN, Lee HJ, Sohn JW, Kim MJ, et al. Evaluation of BACTEC Plus aerobic and anaerobic blood culture bottles and BacT/Alert FAN aerobic and anaerobic blood culture bottles for the detection of bacteremia in ICU patients. Diagnostic Microbiology and Infectious Disease. 2012;73:239-42.

18. McDonalds CP, Rogers A, Cox M, Smith R, Roy A, Robbins $\mathrm{S}$ et al. Evaluation of the 3D BacT/Alert automated culture system for the detection of microbial contamination of platelet concentrates. Transfusion Medicine. 2002;12:303-9.

19. Vollmer T, Hinse D, Schottstedt V, Bux J, Tapernon K, Sibrowski W, et al. Inter-laboratory comparison of different rapid methods for the detection of bacterial contamination in platelet concentrates. Vox Sang. 2012; 103(1):1-9.

20. Mastronardi C, Perkins H, Derksen P, denAdmirant M, Ramirez-Acros S. Evaluation of the BacT/ALERT_3D system for the implementation of in-house quality control sterility testing at Canadian Blood Services. Clin Chem Lab Med. 2010;48(8):1179-87.

21. Savini V. Catavitello C, Astolfi D, Balbinot A, Masciarelli G, Pompilio A, et al. Bacterial Contamination of Platelets and Septic Transfusions: Review of the Literature and Discussion on Recent Patents About Biofilm Treatment. Recent Patents on Anti-Infective Drug Discovery. 2010; 5:168-76.

22. Vollmer T, Dreier J, Schottstedt V, Bux J, Tapernon K, Sibrowski W, et al. Detection of bacterial contamination in platelet concentrates by a sensitive flow cytometric assay (BactiFlow): a multicentre validation study. Transfus Med. $2012 ; 22(4): 262-71$.

23. Blajchman MA. Bacterial contamination and proliferation during the storage of cellular blood products. Vox Sang. 1998;74 Suppl 2:155-9.

24. Macauley A, Chandrasekar A, Geddis G, Morris KG, McClelland WM. Operational feasibility of routine bacterial monitoring of platelets. Transfus Med. 2003;13 (4):189-95.

25. Dunbar NM, Kreuter JD, Marx-Wood CR, Dumont LJ, Szczepiorkowski ZM. Routine bacterial screening of apheresis platelets on Day 4 using a rapid test: a 4-year single-center experience. Transfusion. 2013;53(10): 2307-13.
26. Brecher ME, Means N, Jere CS, Heath D, Rothenberg S, Stutzman LC. Evaluation of an automated culture system for detecting bacterial contamination of platelets: an analysis with 15 contaminating organisms. Transfusion. 2001;41:477-82. 